\title{
Teratogene effekter av antiepileptika
}

\author{
Bernt A. Engelsen \\ Nevrologisk institutt, Universitetet i Bergen, 5021 Haukeland sykehus
}

\begin{abstract}
SAMMENDRAG
Ca. 1 av 200 gravide har epilepsi. Gravide med epilepsi har økt risiko for visse obstetriske komplikasjoner og for å føde barn med medfødte misdannelser. Risikoen for misdannelser synes koblet til bruk av antiepileptika under svangerskapet, og ikke til selve epilepsien. Alle typer misdannelser er økt, men leppeganespalte og nevralrørsdefekter utgjør særlig viktige misdannelser. Årsakene til misdannelsene er multifaktorielle. Bruk av antiepileptika i monoterapi kan sies å gi en individuell risiko for større misdannelser på ca. 4-6\%. Karbamazepin og natriumvalproat gir hhv. 0,5-1\% og 2-3\% risiko for nevralrørsdefekt. Samlet risiko for større og mindre anomalier inkludert dysmorfe ansiktstrekk synes ikke å overstige $10 \%$.
\end{abstract}

\section{ENGLISH SUMMARY}

Engelsen BA. Teratogenic effects of antiepileptic drugs. Nor J Epidemiol 1997; 7 (1): 23-28.

Approximately 1 in 200 pregnant women have epilepsy, and 1 in 250 births are to children of mothers who use antiepleptic drugs (AED). Pregnant women with epilepsy have increased risk for certain obstetrical complications, and for giving birth to children with congenital malformations. The increased risk for congenital malformations seems connected to the use of AED, not to the epileptic syndromes. The etiology of congenital malformations are multifactorial. Use of AED in monotherapy is associated with an individual risk of giving birth to a child with a major malformation of 4-6\%. The specific risk of spina bifida is 0,5 to $1 \%$ for carbamazepine and $2-3 \%$ for sodium valproate.

\section{INTRODUKSJON}

Ca. $0,3-0,5 \%$ av gravide har epilepsi, og 1 av 250 fødsler skjer hos kvinner som bruker antiepileptika (1-4).

Misdannelser og utviklingsanomalier hos fostre har åpenbart multifaktoriell bakgrunn. Virus- og andre infeksjoner, genetiske og miljøfaktorer, vevsskade på grunn av iskjemi, hypoksi eller forstyrrelser i stoffskiftet kan føre til skade eller utviklingsanomali (5-7).

Epilepsitilstanden med bl.a. krampeanfall hos den gravide kan også øke risiko for skader på fosteret ved fall, abruptio placenta $(8,9)$ eller som følge av uvanlige komplikasjoner som f.eks. intracraniell blødning hos foster etter krampeanfall hos mor (10).

Hensikten med artikkelen er ikke å gi en kritisk analyse av forskningsmetodikk og pågående studier, men en kort rapport om sentrale problemstillinger og noen ubesvarte spørsmål vedrørende teratogene effekter av antiepileptika.

Vi vet $\mathrm{i}$ dag at bruk av antiepiletika i svangerskapet øker risiko for misdannelser hos fosteret. Medikamentene synes å være viktigste bidragende faktor. Imidlertid er det ikke undersøkt i tilstrekkelig grad hvorvidt undergrupper av epileptiske syndromer i seg selv øker risiko for misdannelser, og hvorvidt andre faktorer som ernæring, maternell mitokondriell arv etc. bidrar til et komplisert nett av risikomomenter.

Mange studier er retrospektive og beheftet med metodologiske svakheter. Selv nyere prospektive undersøkelser kan ikke kontrollere for alle tenkelige endogene og eksogene risikofaktorer.

\section{MATERNELL EPILEPSI OG OBSTETRISKE PROBLEMER}

Svangerskap har varierende effekt på den gravides epilepsi. Halvparten har uendret anfallsfrekvens $(2,4$, $11,12)$, en tredjedel har økt anfallsfrekvens og resten har sjeldnere epilepiske anfall enn før $(4,13)$. Risikoen for status epilepticus i svangerskapet er 1-2\%.

Hyperemesis (3) og frekvensen av abort og preeklampsi er som hos andre $(3,4)$. Det er økt risiko for intrauterin vekstretardasjon $(2,4,8,12)$. Det kan skyldes epilepsien, antiepileptika $(2,8)$, eller andre endogene og exogene, inkludert sosioøkonomiske, forhold (12).

Sectio og tangfødsel er hyppigere hos epileptikere enn andre. Frekvensen av lav fødselsvekt og prematuritet er mellom 5 og 10\% når den gravide bruker antiepileptika (9). Den perinatale mortalitet er doblet i forhold til gravide som ikke bruker antiepileptika (4), pga. blødninger hos moren og medfødte misdannelser $(2,4,9)$. 


\section{EFFEKTER AV ANTIEPILEPTIKA PÅ FOSTER}

Sannsynlig teratogen effekt av et antiepileptikum ble først rapportert med en kasuistikk i 1963 (14). I en tysk retrospektiv studie av 426 svangerskap hos mødre med epilepsi ble det året etter konkludert med en malformasjonsrate på 2,2\%, som ikke var signifikant forskjellig fra raten i den øvrige befolkningen (15). Senere undersøkelser har vist lavere rate av misdannelser i retrospektive enn prospektive studier av kvinner med epilepsi. Orofasiale spalter og dysmorfe ansiktstrekk som følge av maternell bruk av antiepileptika ble rapportert i 1968 (16). Den forste retrospektive studien som viste signifikant økt risiko for kongenitale misdannelser hos barn av mødre med behandlet epilepsi kom i 1972 (17).

Det er nå enighet om at antiepileptika øker risiko for både større og mindre fosterskader (2,7-9,17-29) (Tabell 1) og at risikoen synes knyttet til antiepileptika og ikke det epileptiske syndromet per se $(7,9,11)$. Risikoen for misdannelser øker med antall $(1-4,8,11)$ og dosen $(9,11,23)$ av antiepileptika. Men mors anfall under svangerskap, hjerneskade eller adferdsvansker (9), samt metabolisering av antiepileptika (24), bidrar.

Det er fortsatt uavklart hvorvidt annen genetisk disposisjon, som f.eks. maternell mitokondriell arv kan bidra signifikant til risiko $(2,7,11-21,30,31)$ (Tabell 2).

\section{DE ENKELTE MISDANNELSER}

Med større skade forståes stort sett medisinsk eller kirurgisk behandlingstrengende skade eller misdannelse. En konsis definisjon av mindre misdannelser synes vanskelig å få etablert og å anvende vitenskapelig $(32,33)$.

Mors bruk av antiepileptika er forbundet med økt forekomst av alvorlige misdannelser i flere organsystemer, som leppe-ganespalter, kardiovaskulære anomalier, skjelett, gastrointestinale, urogenitale og sentralnervøse malformasjoner (1-4,7-12).

Leppe-ganespalter synes å være de hyppigst forekommende misdannelsene og utgjør inntil 30\% av alle misdannelser (9). I to oversiktsartikler er det vist at forekomst av leppe-ganespalte ved bruk av antiepileptika øker med henholdsvis 4,7 ganger raten i kontrollgruppen (7), alternativt at raten av slike misdannelser hos levendefødte øker fra 1,5/1000 i kontrollpopulasjonen til 13,8/1000 hos barn eksponert for antiepileptika (21). Sistnevnte anslag er basert på 28 publikasjoner med 5155 svangerskap hos mødre med epilepsi (21). For disse misdannelsene syntes genetiske faktorer eller epileptiske anfall under svangerskapet ikke å bidra til økt risiko (7). Liknende funn er gjort i studier av andre misdannelser.

En japansk multisenterstudie med prospektive og retrospektive data viste at den totale forekomsten av misdannelser var $1,8 \%$ hos barn født av mødre uten antiepileptika og uten epileptiske anfall under svangerskapet. Forekomsten var $2,6 \%$ hos barn hvis mødre ikke brukte antiepileptika, men hadde anfall under svangerskap, 11,5\% dersom mor brukte antiepileptika, men var uten anfall, og 12,7\% dersom mor brukte antiepileptika og hadde anfall under svangerskapet (11).

Mors og fars epileptiske syndrom kan være en bidragende faktor $(30,34)$, men det er ofte dårlig kartlagt. For eksempel har en undersøkelse vist at spina bifida occulta kan opptre dobbelt så hyppig hos pasienter med juvenil myoklonisk epilepsi, som hos andre med epilepsi (34).

Blant de mindre anomaliene anser mange dysmorfe ansiktstrekk, og anomalier av fingre og tær $(22,32)$. Det er uenighet om hvorvidt dysmorfe ansiktstrekk og lette kognitive forstyrrelser, dvs. lett mental retardasjon hos barn $(35,36)$ kan være følge av mors bruk av antiepileptika. Enkelte undersøkelser har antydet at barn av mødre med epilepsi har lavere generell IQ enn barn av kontrollmødre (IQ 91,7 vs. 96,8) (12). Ved prospektive studier og bedre kontroll av sosioøkonomiske aspekter ble forskjellene mindre og dels ikke signifikante (35). En assosiasjon mellom dysmorfe ansiktstrekk og mental retardasjon er ikke bekreftet $i$ nyere studier (2), og det synes nå ikke å være grunnlag for å hevde at mors bruk av antiepileptika øker risiko for generell svikt i kognitiv funksjon $(2,35)$. Om eventuelle spesifikke kognitive problemer er knyttet til bruk av antiepileptika eller genetisk disposisjon, er uavklart $(35,37)$. Nye studier tyder på at slike kognitive forstyrrelser i stor grad skyldes arvelige faktorer $(35,38)$.

I 1991 refererte Yerby 20 studier med ca. 675345 kontrollsvangerskap og 11754 svangerskap hos mødre med epilepsi (2). Raten av levendefødte misdannede barn var hhv. 1,6-5,6\% hos kontrollene, og 2,3-18,6\% hos mødre med behandling for epilepsi (2).

Variasjonen i raten av misdannelser hos barn eksponert for antiepileptika kan reflektere variasjon $\mathrm{i}$ bruk av antiepileptika, både antall og type medikament. I den japanske multisenterstudien som viste gjennomsnittlig over $10 \%$ malformasjonsrate hos barn eksponert for antiepileptika, var raten 5,5\% ved bruk av kun 2 antiepileptika. Kun 15\% av mødrene hadde monoterapi.

Generelt synes raten av misdannelser i kontrollpopulasjoner å være 2-3\%, og med denne bakgrunn er det anslått en individuell risiko på 4-6\% for misdannelser hos barn født av mødre som bruker antiepileptika i monoterapi $(2,3,9)$.

Barn av mødre med epilepsi har forøvrig økt risiko for epileptiske anfall $(17,38)$. Retrospektivt synes denne risiko ikke knyttet til mors bruk av antiepileptika, men til hvorvidt hun hadde anfall under svangerskapet (39). Muligens reflekterer dette maternell mitokondriell arv, en faktor som kan tenkes også å ha betydning for utvikling medfødte misdannelser. 
variasjon i ernæring, alkohol- og nikotinforbruk, mulige genetiske disposisjoner for misdannelser og forskjellig eksposisjon for exogene teratogener (Tsjernobyl!), viser hvor mange faktorer det må kontrolleres for ved sammenliknende studier. I tillegg kommer sosioøkonomiske forhold, som bl.a. grunnet trygdelovgiving kan være forskjellig fra land til land! Pasienter med liknende epilepsi kan i Norge og USA ha forskjellig opplevelse av økonomiske problemer knyttet til epilepsien (41, Gramstad og Engelsen, upubliserte data).

Sannsynligvis får vi ikke etablert fullstendig kontrollerte studier. Men enkeltfaktorer kan likevel belyses og gi grunnlag for rimelig godt estimat av samlet risiko for misdannelser ved bruk av antiepileptika sammenholdt med ubehandlet epilepsi, gitt sammenliknbare obstetriske data.

\section{TEORIER OM ÅRSAKER TIL FOSTERSKADER}

Kliniske og eksperimentelle undersøkelser av bl.a. fenytoin, natriumvalproat og karbamazepin har gitt alternative forklaringsmodeller på antiepileptikaindusert fosterskade:

1. Antiepileptika gir forstyrrelser i folinsyrestoffskiftet $(1,2,6,42)$. Hypotesen er gammel og støttes av eksperimentelle undersøkelser som viser forekomst av leppe-ganespalter og andre malformasjoner hos dyr på folatfri diett, eller behandlet med folinsyreantagonister (6). Folinsyretilskudd har også vist seg å redusere teratogen skade $(1,2,25,42)$.

2. Alternativt kan enkelte antiepileptika omdannes til toksisk reaktive metabolitter (fenytoin, natriumvalproat og karbamazepin) som f.eks. en arene oksid metabolitt (epoksid) $(2,6,9)$. Slike produkt oppstår ved omdannelse av modersubstansen via cytochrom $\mathrm{P} 450$ isoenzym.

3. Som et tredje alternativ kan føtal hypoksi og iskjemi generere frie radikaler som i sin tur gir teratogene skader i embryonalt vev.

4. Med henblikk på natriumvalproat-indusert spina bifida har forstyrrelser i enten (a) folinsyremethionin stoffskifte eller (b) i endogent vitamin A-/retinolsyre stoffskifte vært foreslått $(43,44)$.
Oksidativ metabolisering av antiepileptika er særlig avhengig av cytochrom P450 isoenzymer som derved regulerer omsetningen av antiepileptika, men også produksjonen av bioaktive metabolitter som kan ha skadelige, evt. teratogene effekter (45-48).

Genetisk betingende forskjeller i cytochrom $\mathrm{P} 450$ isoenzym aktivitet kan forklare individuelle forskjeller i omsetning av enkelte antiepileptika og interaksjoner mellom antiepileptika. De kan også meget vel medvirke til genetiske forskjeller i teratogent potensiale av enkelte antiepileptika (45-48). Stiripentol, et antiepileptikum som hemmer cytochrom $\mathrm{P} 450$, reduserer f.eks. forekomst av fenytoin-induserte misdannelser hos mus (47).

\section{PROFYLAKSE OG PRAKTISKE RÅD}

Behandling er ikke tema for artikkelen, men umiddelbart knyttet opp mot hypoteser vedrørende mekanismene for teratogen skade. Kort summert skal svangerskap hos epileptikere være planlagt, og indikasjonen for fortsatt behandling vurderes $f ø r$ svangerskapet. Under svangerskapet bør antiepileptika doseres lavt, med stabilt serumnivå. Ultralydsundersøkelse bør foretas flere ganger, og spesielt i uke 13-18. Amniocentese er sjelden indisert. Serum folatnivå undersøkes før planlagt konsepsjon (!), og ved for lavt nivå gis 4-5 mg folinsyre daglig. Ved normalt serumnivå og bruk av natriumvalproat bør daglig dose $i$ hele første trimester være 4-5 mg, mens ved andre antiepileptika, er det sannsynlig at 0,4 mg daglig er nok. Da det ikke er dokumentert klinisk relevante bivirkninger av folinsyretilskudd inntil $5 \mathrm{mg}$ daglig (49), kan dosen gjerne opprettholdes i første trimester. Tilskudd med vitamin $\mathrm{K}$ (Konakion) 10-20 mg daglig kan gis siste 2-3 uker ved tegn til blødning. Eventuelt gis vitamin D (400 IE daglig) ved svært lavt serum kalsium og økende anfall. Forøvrig forløses pasienten etter vanlige obstetriske prinsipper, og bør amme som andre.

\section{KONKLUSJON}

Sammenfatningsvis fører maternell bruk av antiepileptika i monoterapi til en dobling av risiko for medfødte misdannelser, med en individuell risiko for teratogen skade på 4-6\%. Natriumvalproat og karbamazepin gir hhv. 2-3 og 0,5-1\% risiko for nevralrørsdefekt. Samlet risiko for større og mindre anomalier inkludert dysmorfe ansiktstrekk synes ikke å overstige 10\%.

\section{REFERANSER}

1. Lindhout D, Omtzigt JG. Pregnancy and the risk of teratogenicity. Epilepsia 1992; 33 (Suppl 4): S41-8.

2. Yerby M. Pregnancy and teratogenesis. In Trimble MR, ed. Women and Epilepsy. John Wiley, Chichester, 1991: 167-92.

3. Hopkins A. Epilepsy and convulsants. Br Med J 1987; 294: 497-501.

4. Meadow R. Anticonvulsants in pregnancy. Arch Dis Child 1991; 66: 62-5.

5. Welch K, Winston KR. Spina bifida. In Myrianthopoulos NC, ed. Handbook of Clinical Neurology, Vol. 6 (50): Malformations. Elsevier Science Publ., 1987; 477-508. 
6. Danielsson BR. Mechanisms of teratogenesis of antiepileptic drugs. Abstract, Scandinavian Symposium on Epilepsy-Pregnancy and Genetic Aspects, Visby, April 1996 (to be published as a Ciba Foundation Symposium volume).

7. Friis ML. Facial clefts and congenital heart defects in children of parents with epilepsy: genetic and environmental etiological factors. Acta Neurol Scand 1989; 79: 433-59.

8. Yerby MS. Risk of pregnancy in women with epilepsy. Epilepsia 1992; 33 (Suppl 1): S23-7.

9. Yerby MS, Devinsky O. Epilepsy and pregnancy. In Devinsky O, Feldmann E, Hainline B, eds. Neurological Complications of Pregnancy (Adv Neurol 64), 1994: 45-63.

10. Minkoff H, Schaffer RM, Delke I, Grunebaum AN. Diagnosis of intracranial hemorrhage in utero after a maternal seizure. Obstet Gynecol 1985; 65 (Suppl 3): 225-43.

11. Nakane Y, Okuma T, Takahashi R, et al. Multi-institutional study on the teratogenicity and fetal toxicity of antiepileptic drugs: A report of a collaborative study group in Japan. Epilepsia 1980; 21: 663-80.

12. Nelson KB, Ellenberg JH. Maternal seizure disorder, outcome of pregnancy, and neurological abnormalities in the children. Neurology 1982; 32: 1247-54.

13. Gjerde IO, Strandjord RE, Ulstein M. The course of epilepsy during pregnancy: A study of 78 cases. Acta Neurol Scand 1988; 78: 198-205.

14. Mullers-Kuppers von M. Embryopathy during pregnancy caused by taking anticonvulsants. Acta Paedopsychiatrica 1963 ; 30: 401-405.

15. Janz D, Fuchs U. Are antiepileptic drugs harmful when given during pregnancy ? German Medicine Monthly 1964; 9: 20-22.

16. Meadow SR. Anticonvulsant drugs and congenital abnormalities. Lancet 1968; ii: 1296.

17. Speidel BD, Meadow SR. Maternal epilepsy and abnormalities of the fetus and newborn. Lancet 1972; ii: 839-43.

18. Bjerkedal T, Bahna SL. The course and outcome of pregnancy in women with epilepsy. Acta Obstetr Gynecol Scand 1973; 52: 245-8.

19. Weber M, Schweitzer Mur J-M, Andre M, Tridon P, Vert P. Epilepsy, anticonvulsants and pregnancy. Arch Fr Pediatr 1977; 34: 374-383.

20. Annegers JF, Hauser WA, Elveback LR, Anderson VE, Kurland LT. Congenital malformations and seizure disorders in the offspring of parents with epilepsy. Int J Epidemiol 1978; 7: 241-247.

21. Kelly TE, Edwards P, Rein M, Miller JQ, Dreifuss FE. teratogenicity of antiepileptic drugs II. A prospective study. Am J Med Genet 1984; 19: 435-443.

22. Janz D, Bossi L, Dam M, Helge H, Richens A, Schmidt D, red. Epilepsy, Pregnancy and the Child. Raven Press, New York, 1982.

23. Dansky LV, Finnell RH. Parental epilepsy, anticonvulsant drugs, and reproductive outcome: Epidemiologic and experimental findings spanning three decades; 2: Human studies. Reprod Toxicol 1991; 5 (4): 301-35

24. Lindhout D. Pharmacogenetics and drug interactions: Role in antiepileptic-drug-induced teratogenesis. Neurology 1992; 42 (4 Suppl 5): 43-7.

25. Delgado-Escueta AV, Janz D. Consencus guidelines: Preconception counseling, management, and care of the pregnant woman with epilepsy. Neurology 1992; 42 (Suppl5): 149-60.

26. Samren EB, Lindhout D, van Duijn CM, et al. Prospective cohort study of pregnancy outcome. Epilepsia 1994; 35 (Suppl 7) 14-15.

27. Dublin M, Manelis J. Epilepsy, pregnancy and offspring of women with epilepsy in Israel. Epilepsia 1994; 35 (Suppl 7): 15.

28. Beaussart M, et al. Outcome of pregnancy in epileptic women. Epilepsia 1994; 35 (Suppl 7): 15.

29. Shakir RA, Abdulwahab B. Congenital malformations before and after the onset of maternal epilepsy. Acta Neurol Scand 1991; 84: 153-6.

30. Dansky L, Andermann E, Andermann F. Major congenital malformations in the offspring of epileptic patients: Genetic and environmental risk factors. In Janz D, Bossi L, Dam M, Helge H, Richens A, Schmidt D, red. Epilepsy, Pregnancy and the Child. Raven Press, New York, 1982: 223-34.

31. Finnell RH, Chernoff GF. Genetic background: The elusive component in the fetal hydantoin syndrome (Editorial comment). Am J Med Genet 1984; 19: 459-62.

32. Janz D. On major malformations and minor anomalies in the offspring of parents with epilepsy. In Janz D, Bossi L, Dam M, Helge H, Richens A, Schmidt D, red. Epilepsy, Pregnancy and the Child. Raven Press, New York, 1982: 211-22.

33. Mackeprang M, Hay S, Lunde AS. Completeness and accuracy of reporting of malformations on birth certificates. HSMHA Health Rep 1972; 87: 43-9.

34. Klepel H, Freitag G. Spina bifida occulta in epilepsy syndromes. Neurology 1992; 42 (Suppl 5): 126-7.

35. Gaily E, Kantola-Sorsa E, Granström M-L. Intelligence of children of epileptic mothers. J Pediatr 1988; 113: 667-84. 
36. van der Pol M, Hadders-Algra M, Huisjes HJ, Touwen BCL. Antiepileptic medication in pregnancy: Late effects on the children's central nervous system development. Am J Obstet Gynecol 1991; 164: 121-8.

37. Lindhout D, Omtzigt JG. Teratogenic effects of antiepileptic drugs: Implications for the management of epilepsy in women of childbearing age. Epilepsia 1994; 35 (Suppl 4): S19-28.

38. Gaily E. Minor anomalies and effects on psychomotor development associated with maternal use of antiepileptic drugs. Abstract, Scandinavian Symposium on Epilepsy-Pregnancy and Genetic Aspects, Visby, April 1996 (to be published as a Ciba Foundation Symposium volume).

39. Ottman R, Annegers JF, Hauser A, Kurland LT. Higher risk of seizures in offspring of mothers than of fathers with epilepsy. Am J Hum Genet 1988; 43: 257-64.

40. Bolton King P, Lie RT, Irgens LM. Spina bifida and cleft lip occurence in newborns of Norwegian women with epilepsy: Changes related to the use of anticonvulsants. Am J Public Health 1996; 86: 1454-6.

41. Gramstad A, Iversen EM, Smievoll AI, Engelsen BA. Preliminary investigation of an inventory for the assessment of psychososial problems in epilepsy (Abstract) Epilepsia 1995; 35 (Suppl 5): S184-5.

42. MRC Vitamin Study Research Group (Nicolas Wald). Prevention of neural tube defects: Results of the Medical Research Vitamin Study. Lancet 1991; 338: 131-7.

43. Wegner $\mathrm{C}$, Nau H. Alteration of embryonic folate metabolism by valproic acid during organogenesis: Implications for mechanism of teratogenesis. Neurology 1992; 42 (Suppl 5): S17-4.

44. Nau H. Valproic acid-induced exencephaly and spina bifida in the mouse as model for mechanistic studies and possible prevention of neural tube defects. Abstract, Scandinavian Symposium on Epilepsy-Pregnancy and Genetic Aspects, Visby, April 1996 (to be published as a Ciba Foundation Symposium volume).

45. Shanks MJ, Wiley MJ, Kubow S, Wells PG. Phenytoin embryotoxicity: Role of enzymatic bioactivation in a murine embryo culture model. Teratology 1989; 40: 311-20.

46. Van Dyke DC, Berg MJ, Olson CH. Differences in phenytoin biotransformation and susceptibility to congenital malformations: A review. DICP 1991; 25 (9): 987-92.

47. Finnell RH, Kerr BM, van Waes M, Steward RL, Levy RH. Protection from phenytoin-induced congenital malformations by coadministration of the antiepileptic drug stiripentol in a mouse model. Epilepsia 1994; 35: 141-8.

48. Levy RH. Cytochrome P450 isozymes and antiepileptic drug interactions. Epilepsia 1995; 36 (Suppl 5): S8S13.

49. Campbell NRC. How safe are folic acid supplements? Arch Intern Med 1996; 156: 1638-44. 